\title{
Storytelling in Online Classes as an Oral Communication Strategy during the Covid-19 Pandemic
}

DOI: https://doi.org/10.47175/rielsj.v2i1.193

\section{| Cristie Ann L. Jaca |}

College of Education, Cebu

Technological University, Cebu

City, Philippines

cristieann.jaca@ctu.edu.ph

\begin{abstract}
The covid-19 pandemic has affected the students' learning mentality as they become passive during online classes due to what is happening around them. The focus of teaching now is to make the students feel comfortable learning despite distractions caused by the pandemic. This paper presents storytelling as an oral communication strategy during online classes to be comfortable and motivated in their learning. This study used the descriptive research method that describes storytelling as an instructional strategy in online classes for students to be engaged and motivated to learn. The study's findings indicate that the use of stories and the act of telling personal stories have developed the students' expressive language and provided students the opportunity to express their ideas in a non-threatening environment. It proved that storytelling during the online class positively impacted the students' oral communication skills. It helped students communicate their thoughts and feelings without fear of being judged. Moreover, it offered opportunities for students to participate in class.

KEYWORDS

online classes; oral communication; storytelling; teaching strategy
\end{abstract}

\section{INTRODUCTION}

The mantra in teaching that says "Start where the learners are" has been encouraged, especially at this coronavirus pandemic. Students have to handle it with care and support in these challenging times; however, very few teachers have really applied this mantra by heart. Students are bombarded with situations with varying degrees of complexities in this new normal due to the pandemic. Learning in the new normal poses challenges in developing oral communication skills among students as the use of online learning platforms like google classroom limits the students' participation. It disrupts students' engagement in-class due to different technological hitches. Students tend to be passive and mentally unstable during online classes that resulted in less class participation. The onset of online learning in the new normal due to the Covid-19 pandemic has transformed the teaching-learning process into a flexible educational platform where learning is accessible and convenient for both students and teachers in times of global crisis. With the current situation, instructional activities must be caring and supportive for students to learn. This paper presents storytelling as an oral communication strategy in teaching students in this new normal. The focus of teaching now is to make the students feel comfortable in learning despite distractions caused by the pandemic. As such, students must be provided with well-planned and engaging activities that will allow them to develop their oral communication skills so they can express themselves and their feelings in their classes without being discriminated against or without feeling being unnoticed.

Language has always been considered an essential component in the delivery of information in the classroom (Jaca \& Javines, 2020) and the new normal requires more 
communicative activities and the use of oral communication strategies to facilitate learning. Students should feel comfortable during online classes to motivate them to learn and engage them in online activities. Telling and sharing stories in class have provided positive results in engaging students to learn. Kim's (2010) study showed that storytelling was an effective pedagogical instrument in improving the language skills of learners who demonstrated interest and pleasure in participating in storytelling activities, whereas little progress was observed in learners with no or little interest in storytelling. Moreover, it demonstrates that storytelling may play an important role in helping learners improve their language skills in L2 but also that it may not help learners much if storytelling is not delivered at an appropriate language level to learners, causing them stress, frustration, and lack of interest in storytelling activities. Similarly, Lucarevschi (2016) presented Atta-Alla's (2012) study that after the learners listened to stories, they participated in different oral and written communicative activities which aimed to offer them the opportunity to work on receptive and productive skills. The positive effect of digital storytelling on developing oral communication skills of students has been proven in the study of Elenein (2019) and even on its impact on consumer brand experience in a case of a firm-originated story (Lundqvist et al.,2013).

For years, storytelling has emerged as a valuable tool in teaching and learning that engages both teachers and students (Robin, B. R., 2008). In recent years, the use of digital storytelling became an innovative pedagogical approach that engages students in deep and meaningful learning (Smeda, N., Dakich, E., \& Sharda, N., 2014). Digital storytelling is used as an embodiment of multimedia production for education purposes. Therefore, this is becoming a part of our lives, and is on the threshold of becoming an important part of teaching and learning as well. All of this is being facilitated by ready access to hardware, such as digital cameras and scanners, in conjunction with easy to use software. Many educational institutions have already been exploring the application of digital storytelling for the past few years (Robin. 2008). (https://slejournal.springeropen.com/articles/10.1186/ s40561-014-0006-3).

Miller (1995) argues that the literature on how personal storytelling is actually practiced in everyday life is highly relevant to the position developed by R. Schank and R. Abelson [see PA, Vol 82:43702; 95-188005-001] / Schank and Abelson say that memory is affected by the social context in which stories are told, and that stories are constructed according to culturally shared norms of coherence / however, if remembering is a matter of telling stories, they have greatly underestimated the extent to which memory is constituted by social and cultural processes. According to Schank (1995), storytelling has multiple possible outcomes depending on the many things that happen and the numerous choices that are made during the process of storytelling, especially when a new story is being constructed but even when an old one is being retold.

Storytelling is a valuable medium for developing the oral language skills of active listening and oral expression (Giron \& Floro, 2016 p.173). This provides a nurturing environment that promotes listening, speaking, reading, writing, and viewing as fun learning experiences. This strategy enables students to listen in order to understand, think critically and understand the texts read; to speak with understanding in order to communicate thoughts and experiences; to read for meaning and understanding; and to write creatively in order to communicate thoughts, ideas, needs, information and experiences (S\&D Malone, 2011). Jaca, et al (2018) espoused that the use of local stories in the classroom can encourage students' oral participation since they can talk about their own experiences in relation to the stories presented. Storytelling gets students to talk and participate in class. It also motivates them to create their own stories. It is a common way of getting not only the students' attention but also in providing them awareness of different cultures. Barbour (2015) 
affirmed that storytelling as a teaching tool encourages the development of values, cultural awareness and a better understanding of others and social inclusion. It is a common way of getting students' attention, teaching them moral lessons, and providing them awareness of different cultures. Telling local and traditional stories in class can broaden the students' cultural perspectives as they become aware of the different stories from different periods of time. It creates a greater impact on learning for teachers and educators with students of all ages and abilities.

Lucarevschi (2016) affirmed that storytelling is one of the oldest forms of human communication. It is being used as entertainment, as a teaching-learning process, and as a promotion for cultural values. In his book on "The Role of Storytelling in Language Learning: A Literature Review" cited studies relevant in using Storytelling Approach in teaching.In Bruner's (1986) words, "Narrative deals in human or human-like intention and action and the vicissitudes and consequences that mark their course. It strives to put its timeless miracles into the particulars of experience and to locate the experience in time and place." Stories can bring abstract principles to life by giving them concrete form. We cannot always give students direct experience with psychological concepts, but stories might come close. (https://www.psychologicalscience.org/observer/storytelling-in-teaching). Sharda (2007) presented a methodology for authoring Educational Media content uisng storytelling using Movement Oriented Design to provide a systematic framework for developing Educational Multimedia narratives using good story telling principles. Stories have been told as a way of passing on traditions, heritage and history to future generations. Even today people continue to tell stories through new digital media tools (Normann, 2015).

\section{RESEARCH METHODS}

This study employed both the quasi-experimental and descriptive-exploratory research methods that investigated storytelling's effect during online classes. It was conducted in a state university in Cebu City, Philippines. Two groups of college classes served as participants of the study. One group served as the experimental group, and the other the control group. Students listened to a story as an introduction to the lesson. They were also encouraged to share their own stories (personal human stories, narratives, fiction) relevant to the lecture's focus. Their participation was based on the scores they get from the activities given after every class discussion. These were recorded and interpreted to determine the students' participation in class.

\section{RESULTS AND DISCUSSION}

The onset of the COVID-19 pandemic has challenged the educational landscape in varied ways. Students have become passive as they attend online classes thus teachers have to engage them so they can participate in class and maximize their learning. The use of storytelling as an oral communication strategy for students to express their ideas and share their views during online classes has encouraged students' engagement during online classes. Storytelling took place during online classroom discussion as students share personal stories using their experiences as they explain their understanding on the topics being discussed. Students were encouraged to share short stories (personal human stories, narratives, fiction) that are relevant to the lecture's focus. Essentially, a story expresses how and why life changes. It begins with a situation in which life is relatively in balance: You come to work day after day, week after week, and everything's fine. You expect it will go on that way (McKee \& Fryer, 2003). This study demonstrated the influence of storytelling and affirms what is stated in the study of (Robin, B. R., 2008) that storytelling is a valuable tool in teaching and learning that engages both teachers and students. 


\section{Students' Online Class Participation}

The online class participation was determined based on the results of the activities that were given after the discussion where storytelling served as an introduction to the lesson. Performance of both groups showed an increase in the mean scores from 15.00 to 16.68 for the control group and from 15.00 to 17.32 for the experimental group, as shown ;

Table 1. The results of students' online class participation, and storytelling as an introduction

\begin{tabular}{llll}
\hline Classes & Result of the activity & Mean & Std. Dev. \\
\hline Control Group & PreActivity & 15.00 & 1.89 \\
& Post Activity & 16.68 & 1.34 \\
\hline \multirow{2}{*}{ Experimental Group } & PreActivity & 15.00 & 1.89 \\
& Post Activity & 17.32 & 1.07 \\
\hline
\end{tabular}

Below are the students' feedback and reactions during the short storytelling activities conducted during online class.

Storytelling is very encouraging and engaging. It is very welcoming and inspiring for students for students to feel comfortable during online class.

Extract \#1: "Storytelling encourages me to learn and I feel supported." RI

Extract \#2: "I think it is important for students to speak without being discriminated. Storytelling makes me encourage to participate." $R 8$

Extract \#3: "Storyteling is pleasurable as I enjoy listening to them while learning new concepts." R10

Extract \#4: "Storyteling is beneficial to me because it makes me feel at home during class." R12

Extract \#5: "Storyteling helps me learn and be comfortable in class." R15

Extract \#6: "Storyteling makes my learning relatable and encourage me to participate." R16

Through storytelling, it makes students take part in class discussions thus giving learners more opportunities for engagement. The students expressed their instant gratification of being allowed to share their stories and to listen to their classmates' stories during class discussions. It has provided them the courage and confidence to participate during online class discussions as it builds a strong connection between and among students. Storytelling help the students to develop their listening and speaking skills thus achieve the intended learning outcomes. Jaca, et al (2018) espoused that the use of stories in the classroom can encourage students' oral participation since they can talk about their own experiences in relation to the stories presented and motivated students to participate in class. Likewise, Atta-Alla's (2012) as also presented in the study of Lucarevschi (2016) described that after the learners listened to stories, they participated in different oral and written communicative activities which aimed to offer them the opportunity to work on receptive and productive skills. Thus, storytelling is a valuable medium for developing the oral language skills of active listening and oral expression as stated in (Giron \& Floro, 2016). 
Extract \#1: "Storytelling is very relaxing. I feel no pressure attending classes and I learn better." R2

Extract \#2: "I become interested in attending my class." $R 5$

Extract \#3: "It makes me participate in class." R11

Extract \#4: "Storytelling makes me comfortable in learning." R14

Extract \#5: "Storytelling makes me feel at home in learning." R17

Extract \#6: "Storyteling connects me to my class and our lesson and its touching." R20

In its simplest form, storytelling remains a powerful communication element, with the narrative being equally as compelling as essays and textbooks. They humanize learning. It offers us the opportunity to connect to like-minded characters or see the world literally from within someone else's skin. Stories touch our emotions and make us laugh, cry, fear, and get angry-a sharp contrast to a plain old presentation. When lessons feel relevant to students, they are more likely to engage, and stories are a perfect vehicle for that. (TeachHub Team, 2015). This also relates to the study of Kim (2014) that her research-participants indicated that learning through storytelling is learner-centered and increases autonomy in developing oral proficiency.

\section{CONCLUSION}

The study's findings affirmed the favorable effects of storytelling as an oral communication strategy and as a means of encouraging students to learn during online teaching, especially during the covid-19 pandemic that affected the students' mental mindset. The use of stories and telling personal stories improved the students' oral communication skills through their participation during online classes. It also developed the students' expressive language and allowed them to express their ideas in a non-threatening environment. It proved that storytelling during the online class positively impacted the students' oral communication skills as it helped students communicate their thoughts and feelings without fear of being judged. It allowed students to express their ideas comfortably, even in an online environment. Storytelling as an oral communication strategy allowed students to feel comfortable participating in class and to feel confident expressing themselves. It serves as a potent teaching approach that can encourage the development of the students' creative and critical thinking skills and gave them a sense of belongingness in class that resulted in meaningful learning. It proved that storytelling during the online class positively impacted the students' oral communication skills. It helped students communicate their thoughts and feelings without concealment

\section{Recommendation}

Personalized storytelling maximizing the use of technology during online teaching and learning is highly recommended in today's digital era as it can increase the students' level of oral class participation.

\section{REFERENCES}

Afrilyasanti, R., \& Basthomi, Y. (2011). Digital Storytelling: A case study on the teaching of speaking to Indonesian EFL students. Language in India: Strength for Today and Bright Hope for Tomorrow, 11, 81-91. 
Atta-Alla, M. (2012). Integrating language skills through storytelling. English Language Teaching (5), 12, 1-13.

Barbour R. (2015). The Power of Storytelling as a Teaching Tool. In: Brewer G., Hogarth R. (eds) Creative Education, Teaching and Learning. Palgrave Macmillan, London

Bruner, J. S. (1986, 2009). Actual minds, possible worlds. Harvard University Press.

Bui, T. T. Q., \& Intaraprasert, C. (2013). The effects of attitude towards speaking English and exposure to oral communication in English on use of communication strategies by English majors in Vietnam. International Journal of Science and Research Publications, 3(2), 1-9.

Elenein, A. H. A. A. (2019). The Effect of Utilizing Digital Storytelling on Developing Oral Communication Skills for 5th Grade Students at Rafah Primary Schools. International Journal of Language and Literary Studies, 1(1).

Giron, P. \& Flojo, O. (2016). 'Literacies in the Mother Tongue-Based Multilingual Education (MTB-MLE): Teaching Strategies'. Mother Tongue-Based Multilingual Education: Guide for Teacher Educators and Students. Lorimar Publishing,Inc.: Manila

Jaca, C.A. \& Javines F. Jr., (2020). Oral Communication Needs of Pre-Service Teachers in Practice Teaching. Randwick International of Education and Linguistics Science (RIELS) Journal. Vol. 1, No. 1, June 2020. Pages 67-73. DOI: https://doi.org/10.47175/rielsj.v1i1.3

Jaca-Delfin C.A. (2017). Cebuano and English Oral Reading Fluency Among Beginning Readers, International Journal of Linguistics and Education. Vol. 2, No. 1, 2017, pp.15. DOI: $10.11648 / \mathrm{j} . \mathrm{ijle}$.20170201.11

Jaca, C.A. Javines Jr. F., Vasquez, B. (2018) Pag-asoy as a Tool in Developing the Students' Oral Language Fluency in the Classroom. International Journal of Education, Culture and Society. Vol. 3, No. 5, 2018, pp. 86-91. DOI 10.11648/j.ijecs.20180305.12

Kim, S. H. (2014). Developing autonomous learning for oral proficiency using digital storytelling. Language Learning \& Technology 18(2), 20-35.

Kim, T. K., \& Park, J. H. (2019). More about the basic assumptions of t-test: normality and sample size. Korean Journal of Anesthesiology, 72(4), 331-335. https://doi.org/10.4097/kja.d.18.00292

Lucarevschi, C. (2016). The role of storytelling in language learning: A literature review. University of Victoria

Lundqvist, A., Liljander, V., Gummerus, J., \& Van Riel, A. (2013). The impact of storytelling on the consumer brand experience: The case of a firm-originated story. Journal of Brand Management, 20(4), 283-297.

Malone, S. \& Malone, D. L. (2011). Two-track approach to introduce reading and writing in students' First Language (L1). www.mlenetwork.org.

McKee, R., \& Fryer, B. (2003). Storytelling that moves people. Harvard business review, 81(6), 51-55.

Miller, P. J. (1995). Personal storytelling in everyday life: Social and cultural perspectives. In R. S. Wyer, Jr. (Ed.), Advances in social cognition, Vol. 8. Knowledge and memory: The real story (p.177-184). Lawrence Erlbaum Associates, Inc.

Normann, A. (2011). Digital storytelling in second language learning: A qualitative study on students' reflections on potentials for learning (Master's thesis, Norges teknisknaturvitenskapelige universitet, Fakultet for samfunnsvitenskap og teknologiledelse, Program for lærerutdanning).

Rappaport, J. (1995). Empowerment meets narrative: Listening to stories and creating settings. American Journal of community psychology, 23(5), 795-807. 
Robin, B. R. (2008). Digital storytelling: A powerful technology tool for the 21 st century classroom. Theory into practice, 47(3), 220-228.

Schank, R. C. (1995). Tell me a story: Narrative and intelligence. Northwestern University Press.

Smeda, N., Dakich, E. \& Sharda, N. (2014) The effectiveness of digital storytelling in the classrooms: a comprehensive study. Smart Learn. Environ. https://doi.org/10.1186/s40561-014-0006-3.

Sharda, N. K. (2007, September). Authoring educational multimedia content using learning styles and story telling principles. In Proceedings of the international workshop on Educational multimedia and multimedia education (pp. 93-102).

Storytelling in the Classroom as a Teaching Stragtegy. The TeachHub Team. August 8, 2015 Retrieved from: https://www.teachhub.com/classroomactivities/2015/08/storytelling-in-the-classroom-as-a-teaching-strategy/ 